\title{
Introduction to the 80th Anniversary Issue of Digestive Diseases and Sciences
}

\author{
David T. Rubin
}

Published online: 27 December 2013

(c) Springer Science+Business Media New York 2013

This issue of Digestive Diseases and Sciences commemorates its 80th year of continuous publication of a journal originating as the American Journal of Digestive Diseases and Nutrition [1]. In honor of this special publication, the cover has been designed to resemble the initial issue published in 1934. The issue includes facsimiles of the first pages of five representative articles published in Volumes 1 and 2, which are included for our readers' enjoyment [2-6]. Three of these articles are accompanied by a historical commentary.

The more I have worked in the field of gastroenterology, the more I appreciate the history of medicine and, more specifically, the history of gastroenterology as a clinical field and as a science. Digestive Diseases and Sciences has a fascinating and varied history over its 80 years, from its early days as a small journal, to its recognition and a time when it was the official journal of the American Gastroenterological Association, to a time when its quality fell significantly, to its resurrection, and, ultimately, to its fine form and increasing quality that we know today.

The articles chosen by our current and esteemed editorin-chief, Dr. Jonathan Kaunitz, represent some of the early clinical descriptions of disease and technology in gastroenterology, and in many ways are fascinating portrayals of the future of our field. They include a description of the early use of radiation to treat bacterial infection of the perianal area, resembling what is now known as Fournier's gangrene, early descriptions of regional enteritis by Burrill Crohn himself, the technical description of the emerging use of rigid gastroscopy by none other than

D. T. Rubin $(\bowtie)$

University of Chicago Medicine, Chicago, IL, USA

e-mail: drubin@medicine.bsd.uchicago.edu
Rudolf Schindler, and an additional description of spastic colitis and what would later be called "irritable bowel". Reading these descriptions reminds us of the importance of astute and careful clinical observations, the meticulous and sometimes painstaking requirement of data collection that advances technology, and, in some ways, both how far we have come as a field and, in other ways, how much further we have yet to go.

Reflecting on these descriptions and conditions, we certainly have become better at diagnosing these disorders and describing the associated syndromes, but we have yet to cure the inflammatory and functional condition described. We have cured many bacterial infections and have revolutionized the approach to such problems since these descriptions from the 1930s. There has been remarkable progress in endoscopic technology, yet the invited commentary by Drs. Leung and Gelrud suggests that technological advances may have stalled in recent years.

I was invited to be an associate editor of Digestive Diseases and Sciences in 2008 by then editor-in-chief Dr. Emmet Keeffe. I remember the 'phone call from him as though it were yesterday. He was a man with vision and a man with a purpose, and I could not say "no" when he described his plans for this journal, which had in recent years waned in its success and popularity.

It was an honor working with Dr. Keeffe and watching him resurrect this publication. I know he would be so proud were he able to see its ongoing success and the improvement in quality and impact factor that has been achieved in the last $5 \frac{1}{2}$ years. I miss him and I know that the gastroenterology community lost a great leader to whom we are forever grateful.

In the years that I have worked on this journal in the area of inflammatory bowel disease, I have witnessed the number and quality of submissions steadily increasing, and 
the increasing willingness of our colleagues to serve as peer reviewers. It has been a joy to participate in this ongoing project and to contribute to the knowledge and literature in our field. We have ranged from quite good basic science, to translational works that offer novel insights into disease pathogenesis, to excellent clinical studies including interventional therapies as well as epidemiologic and social sciences. The journal serves its academic partner, the Gastroenterology Research Group, well, representing and serving our field in an excellent fashion.

It remains an honor to contribute to the journal and an exciting time for us to reflect on its 80 -year history.

\section{References}

1. Keeffe E. Digestive Diseases and Sciences-past, present, and future. Dig. Dis. Sci. 2009;54:1-4.

2. Crohn B. The broadening conception of regional ileitis. Am. J. Dig. Dis. Nutr. 1934;1:97-99.

3. Crohn B. Functional and nervous disorders of the stomach and alimentary tract. Am. J. Dig. Dis. Nutr. 1934;1:773-777.

4. Felsen J. Clinical notes concerning distal ileitis as a manifestation of bacillary dysentery. Am. J. Dig. Dis. Nutr. 1934;1:782-783.

5. Hayes HT. Peri-rectal streptococcal cellulitis. Am. J. Dig. Dis. Nutr. 1934;1:413.

6. Schindler R. Gastroscopy with a flexible gastroscope. Am. J. Dig. Dis. Nutr. 1935;2:656-663. 


\section{Clinical Notes Concerning Distal lleitis as a Manifestation of Bacillary Dysentery}

By

JOSEPH FELSEN, M.D.

NEW YORK CITY. NEW YORK

$\mathbf{R}^{\mathrm{B}}$ ECENT investigations have shown that bacillary dysentery, notably the Sonné-Duval and atypical Flexner types, may manifest itself clinically in many bizarre forms. Symptomless, constipated, meningitic and appendicular types of bacillary dysentery have been described (1-2). The present communication deals with distal ileitis which may be defined as "an acute inflammation of the terminal ileum, accompanied by mesenteric adenitis and caused by $B$. dysenteriae".

\section{CLINICAL FEATURES}

The usual history is that of a dietary indiscretion, following which the patient complains of anorexia, lassitude and headache, sometimes accompanied by vomiting. Abdominal pain may not be a prominent feature for several days, but when it occurs, there is definite localization to the right, lower quadrant. Also, there may be some localization in or near the left, lower quadrant. Tenderness generally is present, at or to the left of McBurney's point; it may be manifested on "rebound" and tends to shift with changing the position of the body. Spastic ileum and sigmoid occasionally are felt through a thin abdominal wall. Diarrhea is not a constant feature, but usually occurs at some time within the first week of the disease. The diarrhea may be profuse and constant or transient. It may be preceded, or succeeded, by constipation but, on the other hand, obstinate constipation may be present during the entire course of the disease. This appears strange in view of the commonly accepted understanding of typical bacillary dysentery. Repeatedly we have observed this phenomenon, however, in recent outbreaks of Sonné-Duval and atypical Flexner dysentery. This feature often is misleading, erroneously eliminating this infection from clinical consideration as a cause of a set of symptoms which usually are interpreted as indicating acute appendicitis. The pyrexia generally is quite moderate; there is a normal leucocyte count or even leucopenia early in the disease.

At operation, should it be performed, the appendix appears grossly to be normal, but the terminal ileum is reddened and its wall is distinctly thickened and edematous, giving the impression of primary, acute inflammation. The picture may be segmental, the redness and thickening stopping abruptly at a point approximately $30 \mathrm{~cm}$. above the ileocecal valve. Beyond this the

Submitteri Novembe: 7,1934 intestine appears to be healthy. The mesenteric vascular loops and arborizations are congested and the mesenteric nodes are enlarged, particularly on either side of the ileum and at the ileocecal angle. A clinical diagnosis of "mesenteric adenitis" usually is made, though such pathology simply is one manifestation of bacillary dysentery, just as terminal ileitis is another.

The post-operative course following appendectomy, which is the usual therapeutic procedure, is governed by the systemic effects of the bacillary dysentery. The disease, as encountered up to the present, runs a rather mild course with gradual subsidence of symptoms and pyrexia, and terminates in uncomplicated cases, in three to five weeks. Nothing as yet can be said with regard to the ultimate regression of the terminal ileitis. This is of particular interest in connection with the etiology of "idiopathic ulcerative colitis" and its extension to, or independent involvement of, the ileum.

It appears quite evident that some of these cases are instances of bacillary dysentery. Unless the feces are cultured early in the disease and repeated agglutination studies are made against typical and atypical dysentery strains, the diagnosis will not be proved. Our experience in the past three months is limited to five cases in three of which the clinical, operative, cultural and serological findings were those of atypical Flexner dysentery. The other two were of the Sonné-Duval type.* Only an adequate follow-up, which is now being carried out, will clarify the possible relationship between bacillary dysentery and idiopathic ulcerative colitis.

Since attention has been called to the appen. dicular form of bacillary dysentery, careful clinical and bacteriological study has eliminated operative interference in some cases. Certain of these patients had symptoms and signs suggestive of ileal involvement. All, including the cases mentioned above, apparently made complete recovery. If our interpretation of the pathology is the correct one, the lesion described represents the earliest stage in terminal ileitis inasmuch as infection preceded symptoms by only one or two weeks.

It is reasonably certain that, in some patients, the acute lesions may fail to heal, secondary nonspecific infection occurs, $B$. dysenteriae and the

*Two other cases with typical operative finclings were studieil too
late after discharge from the hospital to secure corroborative agglutination, cultural and ilagnostic phage tests. 


\section{PERI-RECTAL STREPTOCOCCAL CELLULITIS*}

\section{REPORT OF A CASE}

\section{By}

HERBERT T. HAYES, M.D., F.A.C.S. HOUSTON, TEXAS

$\mathrm{C}^{\wedge}$ ASE History: Mrs. B. D. White, age 40, was admitted to the Memorial Hospital on February 2, 1934, complaining of hemorrhoids. Patient stated that she had had hemorrhoids for about twenty years and that they had given her great annoyance. They bled profusely, prolapsed badly with each stool and frequently induced severe attacks of pain. At intervals she ran a little afternoon temperature.

General examination was essentially negative, urine analysis normal; the blood count exhibited a slight secondary type of anemia. Rectal examination revealed very large prolapsing, ulcerated hemorrhoids.

The patient was operated upon February 3, under spinal anesthesia (50 mgs. of novocain) by the ligature and excision method. One-half per cent "diothane" was injected around the sphincter. The night following the operation the temperature was 103 degrees. Nothing abnormal could be seen about the rectum.

February 4, patient had a chill and her fever stayed around 102 degrees and on February 5 , went to 104 degrees. At this time, there was definite induration on both sides of the rectum, not so marked posteriorly. On February 6, patient continued with chills and fever and on this date, she was given a gas anesthetic and the hardened area on both sides of the rectum was incised freely but no pus was exuded. On the right side, however, there was a serosanguineous discharge.

The peri-anal induration extended about two inches laterally and almost the same distance posteriorly, but was not marked in the perineal body. It also extended for about two inches up in the wall of the rectum. The mucosa of the rectum appeared normal. Cultures were taken from the base of the wound on each side by $\mathrm{Dr}$. Myers.

The patient's temperature continued high during the next day, February 7 , at which date the laboratory report showed a pure culture of streptococci. On the advice of the roentgenologist, Dr. Leonard Myers, treatment with X-rays was begun. The temperature dropped to 101.6 degrees within twelve hours after the first X-ray treatment. In less than eighteen hours, the wounds on both sides of the anus were draining a grayish-white, serosanguineous material very profusely. Subjectively the patient felt much better. On the next day and the day following she was given further X-ray treatments. During this time the wound drained profusely and the areas around the rectum softened rapidly.

The following dosage of X-rays was given:

2-7-34: Spark gap, 5 in.; M. amperes 3 ; no filters; distance, 10 in.; time, 3 min.

2-8-34: Spark gap, 5 in.; M. amperes 3 ; no filters; distance, 10 in.; time, $3 \mathrm{~min}$.

2-9-34: Spark gap, 5 in.; M. amperes 3 ; no filters; distance, $10 \mathrm{in}$; time, $3 \mathrm{~min}$

On the night of the 9th, patient's temperature became normal and did not go above 99 degrees after - Read before the Annual Session of the American I'roctulogic Association.
Clereland, Ohio. June 11.12. 1934 . Submitted July 22, 1934, 11-12." 1934 . this time. Subjectively she was well; the hardness about the rectum had disappeared entirely. The sinuses gradually dried up; there was no communication with the rectum, no resultant fistulae and only one small, draining sinus when she left the hospital on February 20. A culture of the discharge from the wound, ten days after cessation of the X-ray treatments, proved it to be entirely sterile.

Comment: Due to the rarity of this condition as a complication of rectal operations, the literature available at the Library of The American College of Surgeons was reviewed; nothing of like nature could be found. The Transactions of the American Proctologic Society contained no cases similar to that being discussed. A review of the literature of the New York Academy of Medicine revealed three such postoperative complications. Dr. H. Smith of Kings College Hospital, in reporting over 500 hemorrhoidectomies in 1875 and in 1878, stated that he had observed two patients who developed erysipelas of the rectum, postoperatively. One of these patients was extremely, almost fatally ill. L. Stein, Germany, in 1896, reported that, in 300 cases operated for hemorrhoids, he noted but one case of erysipelas. Pruitt, Gant, Lynch and others mention the fact that erysipelas of the rectum occasionally occurs but describe no specific case. Other authors mention the fact that streptococci often are found around the rectum, especially in instances of pruritus and that their presence is a potential danger in rectal operations, but report no instances of the organism's actually causing postoperative damage.

In the case here reported, the streptococci evidently were in the perirectal tissues and were carried into the wound at the operation by trauma or by the needle. This, apparently, accounted for the localized cellulitis.

While I was familiar with the use of X-rays in the treatment of erysipelas, I should not have considered employing it but for the suggestion of the roentgenologist. He predicted before the treatment that such therapy would have a very striking effect should it prove beneficial at all, that the inflammation immediately would begin to subside and a fistula would not follow. However, I was extremely dubious because the patient was so extremely ill. Not having had personal experience, I was unable to see how this prompt benefit could be predicted. It is to be noted that the patient's improvement began immediately after the first treatment and that subsequent treatments accelerated the beneficial results so that the patient became entirely well within a few days.

It is surprising that infections around the rectum are not more common. Apparently the local immunity of the tissues in this region is a protective barrier.

Caution: It should be emphasized that roentgen therapy to the perianal zone, whether for postoperative infection or for the treatment of pruritis ani, should never be exhibited subsequent to the application of oils, ointments or grease-containing suppositories. If X-ray treatments are given in the presence of such medicaments, very serious, extensive, tissue sloughs may follow, often with startling rapidity. 